\title{
Prediction Method of DC Bias in DC-DC Dual-Active-Bridge Converter
}

\author{
Liangcai Shu, Wu Chen, and Zhanfei Song
}

\begin{abstract}
The dual-active-bridge (DAB) converter attracts more and more attentions due to its ability of bidirectional power transmission and high conversion efficiency. The adoption of highfrequency transformer provides galvanic isolation, but also brings the possibility of dc bias. In this paper, the causes of dc bias have been analyzed and relevant calculation methods are derived in details. With the calculation methods, the dc bias magnetizing current can be predicted considering the inconsistency of semiconductor switches and driver signals. In other words, if the maximum permitted dc bias of the transformer is given, the range of the inconsistency of semiconductor switches and driver signals can be obtained which helps guide the selection of semiconductor devices and design of the transformer. Therefore, extra flux balancing method can be avoided and the overall cost and volume will be further reduced. Additionally, simulation and experimental results show great agreement with the theoretical analysis.
\end{abstract}

Index Terms-DC bias, dual-active-bridge converter, prediction method.

\section{INTRODUCTION}

$\mathrm{T}$ HE dual-active-bridge (DAB) converter has been widely adopted in the applications for bidirectional power transmission, such as energy storage system [1]. It comprises two active H-bridges and one high-frequency transformer to achieve large voltage transfer ratio and galvanic isolation. At present, the work mainly focuses on the control strategies of the DAB converter. The representative control methods including single-phase shift (SPS), dual-phase-shift (DPS) and triplephase-shift (TPS) control [2]-[8], aiming to reduce current stress, widen power transmission range and improve conversion efficiency, especially the latter two control strategies. On the other hand, due to the adoption of high-frequency transformer, the dc bias of the transformer needs to be tackled, which can be classified into transient dc bias and steady dc bias. For the transient dc bias which always occurs with the abrupt change of phase-shift angle or input/output voltages, various transient phase shift control strategies are proposed to eliminate the phenomenon [9], [10]. For the steady dc bias, the dc excitation

Manuscript received November 16, 2018. This work was supported in part by National Key Research and Development Program of China (2018YFB0904100), in part by Science and Technology Project of State Grid (SGHB0000KXJS1800685), in part by the Scientific Research Foundation of Graduate School of Southeast University (YBPY1933). (Corresponding author: Wu Chen.)

All authors are with the Center for Advanced Power-Conversion Technology and Equipment, School of Electrical Engineering, Southeast University, Nanjing 210096, China (e-mail: 18362961507@163.com; chenwu@seu.edu. cn; zhanfeisong@126.com).

Digital Object Identifier 10.24295/CPSSTPEA.2019.00015 to the transformer can be caused by non-ideal behavior of the system components, including unmatched turn-on/turn-off times, gate driving signal delays and inconsistency between the parameters of semiconductor devices [11].

In order to eliminate the dc bias of the transformer, various flux measuring and balancing methods have been proposed [11]-[18]. The flux balancing method mainly includes two types: passive balancing and active control. A blocking capacitor connected in series with the winding of the transformer or an air-gap inserted into the core's magnetic path are the main passive balancing methods to eliminate or alleviate the dc bias of the transformer [12], [13], in which no extra control strategy or monitoring devices are needed. However, the blocking capacitor can result in a lowfrequency oscillation in response to variations in switching modes, and cause excessive low-frequency EMI [12]. Moreover, this approach can increase the power loss and the volume. Additionally, the air-gap does not eliminate the dc flux component. Hence, the active flux control methods were proposed [11], [14]-[18]. In order to control the dc magnetization of the core, the flux must be measured dynamically, and the flux measuring methods can be mainly classified into flux measurement and current measurement. For the flux measuring methods, extra processing or components such as magnetic ear [11], a slot in the core legs [14], airgap in the magnetic flux [15], specific type of magnetic core [16], or special sensors are needed to dynamically detect the variation of the flux. For the current measuring methods, the primary and secondary winding currents are sampled to monitor the variation of the magnetizing current [17], [18]. Almost all the measuring methods require high sampling rate and precision, and analog-to-digital converters are even needed [17], [18], which increases the complexity and the overall cost.

With the development of the semiconductor devices manufacturing, the consistency between switches can be guaranteed within certain range. As long as the inconsistency of switches and driving circuits is smaller than certain limitation, the dc bias in the high-frequency transformer can be tolerated. Hence, one calculation method of the dc bias magnetizing current seems necessary, which can also be used to predict the required range of inconsistency with the maximum permitted dc bias magnetizing current given. This can guide the selection of semiconductor devices and the design of transformer, so that extra flux balancing methods can be avoided. One calculation method of the dc bias magnetizing current is proposed in [19] for the zero-voltageswitching (ZVS) converters with the consideration of the 


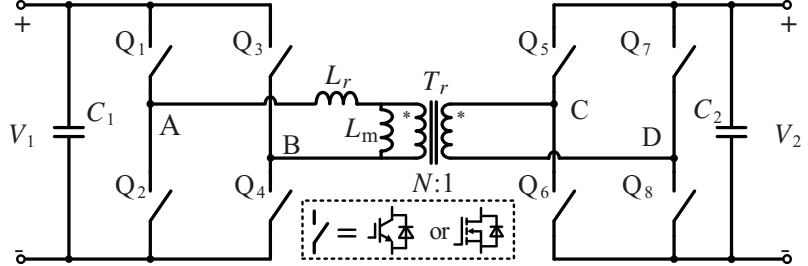

Fig. 1. Typical topology of the DAB converter.

parasitic capacitors in parallel with the switches. However, the calculation equation proposed in [19] is somewhat idealized to calculate the dc bias caused by the inconsistency of devices due to the neglect of on-resistance of the switches and windings. Hence, there is few methods to calculate the maximum dc bias magnetizing current considering the inconsistency of switches and driving circuits.

Considering the inconsistency of switches and driving circuits in practical circuit, a novel method of predicting the maximum dc bias magnetizing current of the DAB converter is proposed in this paper. The DAB converters with IGBTs and MOSFETs are analyzed separatly in the paper for the DAB converters with different semiconductor devices have different current paths in some switching modes. The equivalent models are built in Section II firstly and the generation of dc bias is analyzed in Section III. Then, the prediction method is derived in Section IV and examples are given to introduce the predicting procedure in Section V. Experiments are also made to verify the theoretical analysis in Section VI and conclusions are made in Section VII.

\section{Equivalent Model of DAB Converter With IGBTs AND MOSFETs}

In this section, equivalent models of the DAB converters employing IGBTs and MOSFETs are built to conduct the derivation of dc bias magnetizing current. A typical configuration of the DAB converter is shown in Fig. 1. The inductor $L_{r}$ is the leakage inductor of the transformer $T_{r}$ or the summation of the leakage inductor and an external inductor. $L_{\mathrm{m}}$ is the magnetizing inductor of $T_{r}$. The turns ratio of $T_{r}$ is $N: 1$, and the primary and secondary winding resistances are set as $r_{\mathrm{p}}$ and $r_{\mathrm{s}}$, respectively. The anti-paralleled diodes or body diodes of $\mathrm{Q}_{1} \sim \mathrm{Q}_{8}$ are denoted as $\mathrm{D}_{1} \sim \mathrm{D}_{8}$. In order to simplify the analysis, the transient turn-on or turn-off processes of the switches are neglected.

Because the specific derivation of magnetic flux density dc component $B_{\mathrm{dc}}$ is affected by the employment of IGBTs or MOSFETs, the two situations are analyzed separately here and the equivalent models are built in Fig. 2. For IGBTs and diodes, it is assumed that the on-state voltage $V_{\mathrm{CE}}$ and forward voltage drop $V_{\mathrm{F}}$ are constant, while for MOSFETs, their onstate resistances $R_{\mathrm{ON}}$ are assumed to keep constant. Hence, the parameters in Fig. 2 possess different meanings in IGBTs and MOSFETs applications, which is shown in Table I. For the voltages across $\mathrm{Q}_{1} \sim \mathrm{Q}_{8}$ and $\mathrm{D}_{1} \sim \mathrm{D}_{8}$ have been represented as the parameters $R_{\mathrm{p}} / R_{\mathrm{s}}$ and $v_{\mathrm{dp}} / v_{\mathrm{ds}}, v_{\mathrm{AB}}$ and $v_{\mathrm{CD}}$ in Fig. 2 can
TABLE I

Specific Explanations of Parameters in Fig. 2

\begin{tabular}{ccc}
\hline \hline & IGBTs Applications & MOSFETs Applications \\
\hline$R_{\mathrm{p}} / R_{\mathrm{s}}$ & 0 & $\begin{array}{c}\text { Summation of resistance of } \\
\text { on-state MOSFETs } \\
\left(R_{\mathrm{pM}} / R_{\mathrm{SM}}\right)\end{array}$ \\
\hline & $\begin{array}{c}\text { Summation of forward } \\
\text { voltages across ON switches } \\
\text { or diodes on primary and } \\
\text { secondary sides }\left(v_{\mathrm{dpp}} / v_{\mathrm{ds}}\right)\end{array}$ & $\begin{array}{c}\text { Summation of the voltage } \\
\text { drops across conducted diodes } \\
\text { on primary and secondary } \\
\text { sides }\left(v_{\mathrm{dpM}} / v_{\mathrm{dsM}}\right)\end{array}$ \\
\hline$v_{\mathrm{AB}} / v_{\mathrm{CD}}$ & $\begin{array}{c}\text { Voltage across points A and B (C and D) of the DAB } \\
\text { converter employing ideal switches in Fig. 1 }\end{array}$ \\
\hline$r_{\mathrm{p}} / r_{\mathrm{s}}$ & Resistance of primary $/$ secondary windings \\
\hline \hline
\end{tabular}

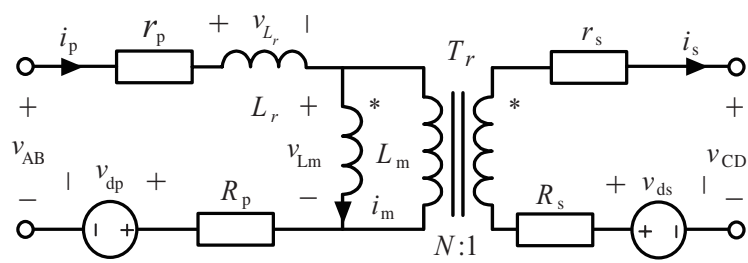

Fig. 2. Equivalent model of the DAB converter.

be seen as the voltage across $\mathrm{A}$ and $\mathrm{B}(\mathrm{C}$ and $\mathrm{D})$ of the $\mathrm{DAB}$ converter employing ideal switches. Hence, $v_{\mathrm{AB}}$ and $v_{\mathrm{CD}}$ are only affected by the voltages $V_{1}$ and $V_{2}$, the on/off states of $\mathrm{Q}_{1} \sim \mathrm{Q}_{8}$ and $\mathrm{D}_{1} \sim \mathrm{D}_{8}$.

\section{Analysis of the Generation of DC Bias}

As aforementioned, various factors can cause the magnetic flux density dc component $B_{\mathrm{dc}}$, which can be classified into two types: unmatched turn-on/off times and the inconsistency between the devices. The unmatched turn-on/off times are usually caused by duty cycle loss, gate driving signal delay and so on, while the inconsistency refers to the difference between the on-state resistances or forward voltages of devices caused by differences in connection types, heat dissipation or device manufacturing.

\section{A. Unmatched Turn-on-off Times}

When the power is transmitted from $V_{1}$ to $V_{2}$ and no dc bias occurs, the typical waveforms of the DAB converter with SPS control strategy are shown in Fig. 3, in which the phase-shift time is $t_{\varphi}$ and the dead time is $t_{\mathrm{d}}$. And the specific ON switches in each mode are given in Table II. When discussing the effect of unmatched turn-on/off times, parameters of the switches are assumed to be consistent.

For the DAB converters with IGBTs, current $i_{\mathrm{p}}$ flows through the anti-paralleled diodes of $\mathrm{Q}_{1}$ and $\mathrm{Q}_{4}$ during the time interval $\left[t_{0}, t_{2}\right]$. Whenever $\mathrm{Q}_{1}$ and $\mathrm{Q}_{4}$ areturned on, as long as it is later than $t_{0}$ and earlier than $t_{2}$, operating state of the converter will not be affected. Hence, the inconsistent time when $\mathrm{Q}_{1} \sim \mathrm{Q}_{8}$ are turned on will not cause dc bias. 


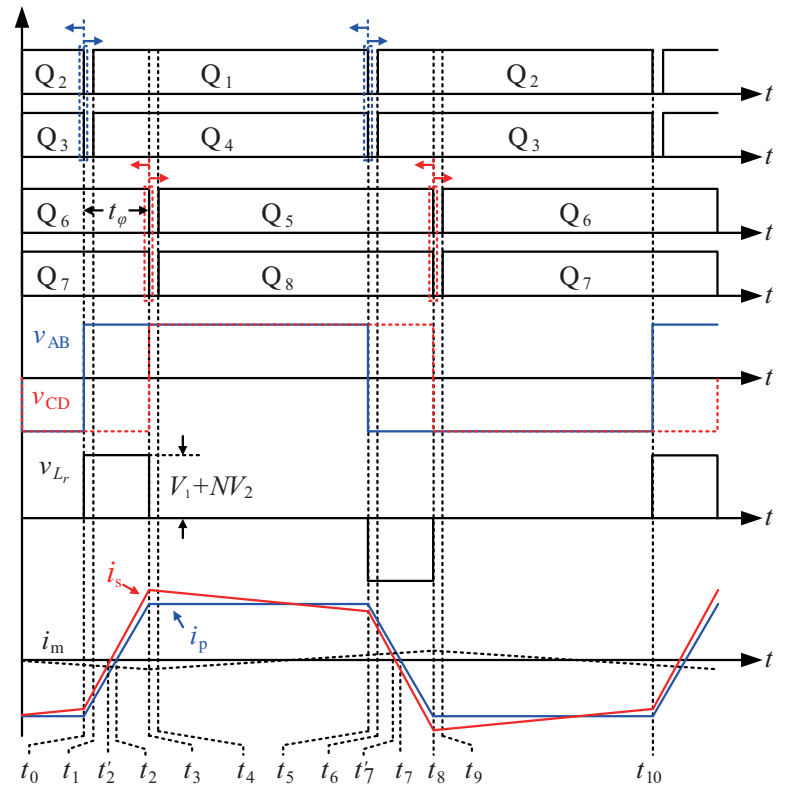

Fig. 3. The typical waveforms of the DAB converter with SPS control.

However, when MOSFETs are adopted as switches, current $i_{p}$ flows through $D_{1}$ and $D_{4}$ during the dead zone $\left[t_{0}, t_{1}\right]$, and flows through the MOSFET channel as soon as $\mathrm{Q}_{1}$ and $\mathrm{Q}_{4}$ are turned on. So unmatched turn-on times will introduce an extra mode. Assuming that $\mathrm{Q}_{1}$ is early turned on, current $i_{p}$ will flow through $\mathrm{D}_{1}$ and $\mathrm{Q}_{4}$ before $\mathrm{Q}_{1}$ is turned on. For the voltage drops of the body diodes and the voltages across the MOSFETs are different, the voltage across $L_{r}$ changes and the variation of $i_{\mathrm{p}}$ in two half switching cycle can be unbalanced. Thus, the dc bias of $i_{\mathrm{p}}$ is generated. Moreover, duration of this extra mode is so short that the effect of inconsistent voltage across devices is limited and the dc bias of $i_{\mathrm{p}}$ will be small, which will be analyzed with mathematic derivation in the next section. For the secondary side of the DAB converter, the switching modes are not affected and no dc bias is generated, which will also be verified in the next section.

When the switches are early turned off or the turn-off time is delayed, the operating state will change and the dc bias will be generated in both IGBTs and MOSFETs applications. The situation where $\mathrm{Q}_{2}$ is turned off earlier than the expected time is taken as an example to introduce how the dc bias is generated. As shown in Fig. 4, when $\mathrm{Q}_{2}$ is early turned off, $i_{\mathrm{p}}$ increases before the expected time $t_{0}$. The variation of $i_{\mathrm{p}}$ during $\left[t_{0}, t_{3}\right]$ becomes larger than that during $\left[t_{5}, t_{8}\right]$, resulting in the positive dc bias of $i_{\mathrm{p}}$. At the same time, the positive dc bias of $i_{\mathrm{p}}$ causes a positive voltage across the resistances $r_{\mathrm{p}}$ and $R_{\mathrm{pM}}$, which can counteract the extra variation of $v_{L_{r}}$ during $\left[t_{0}, t_{3}\right]$ and reduce the increment of the dc bias of $i_{\mathrm{p}}$. Similarly, the secondary side of the DAB converter is not affected either. Finally, the steady operating state under positive dc bias is achieved.

\section{B. Inconsistency of the Devices}

For the DAB converters with IGBTs, it is assumed that the

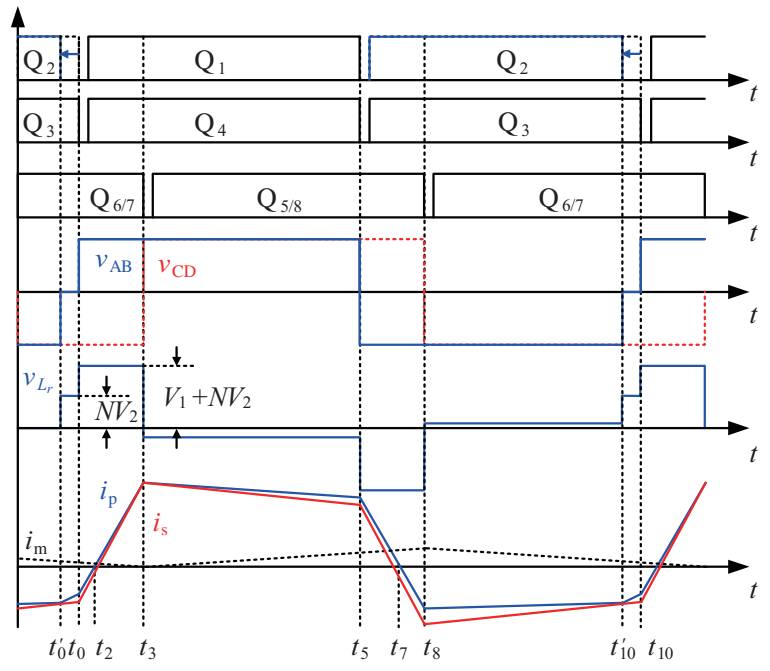

Fig. 4. The waveforms of the DAB converter when $\mathrm{Q}_{2}$ is early turned off.

voltage drop across anti-paralleled diode $\mathrm{D}_{1}$ is smaller than that of other switches. When $\mathrm{D}_{1}$ conducts, the voltage across $L_{r}$ will reduce. So the amplitude of the volt-seconds across $L_{r}$ during $\left[t_{0}, t_{2}\right]$ will become smaller than that during $\left[t_{5}, t_{7}\right]$, resulting in the variation of $i_{p}$ during $\left[t_{0}, t_{2}\right]$ to be smaller than that during $\left[t_{5}, t_{7}\right]$. Hence, the negative dc bias of $i_{\mathrm{p}}$ is generated. Similarly, the negative dc bias of $i_{\mathrm{p}}$ causes a negative voltage across the resistance $r_{\mathrm{p}}$, which can compensate the loss of $v_{L_{r}}$ during $\left[t_{0}, t_{2}\right]$ and reduce the decrement of the dc bias of $i_{\mathrm{p}}$. However, the operating state of the secondary side is not affected. Hence, the final steady state under negative dc bias can be obtained. In addition, the similar analysis can be applied to the DAB converters employing MOSFETs.

\section{Derivation of DC Bias Magnetizing Current}

The derivation of dc bias magnetizing current depends on the type of selected switches, so this section is divided into two parts to introduce the calculation method for IGBTs and MOSFETs, respectively. Before the derivation, following assumptions are made to simplify the derivation.

1) The DAB converter is controlled with SPS strategy;

2) The capacitors $C_{1}$ and $C_{2}$ are large enough to keep $V_{1}$ and $V_{2}$ stable, which satisfies $V_{1}=N V_{2}$;

3) The capacity of $T_{r}$ is large enough to tolerate the magnetic flux density dc component $B_{\mathrm{dc}}$ and its magnetizing inductance keeps constant.

\section{A. IGBTs Applications}

Considering the forward voltages across the switches and primary/secondary winding resistances of the transformer, the voltage across $L_{\mathrm{m}}$ can be calculated with (1). When inconsistency occurs, $v_{L_{\mathrm{m}}}$ will deviate from the expected value, causing unexpected variation of $i_{\mathrm{p}}$ and dc bias.

$$
v_{L_{\mathrm{m}}}=v_{\mathrm{AB}}-r_{\mathrm{p}} i_{\mathrm{p}}-v_{\mathrm{dpI}}-v_{L_{r}}
$$


TABLE II

On-State List of Each Switch During a Switching Cycle

\begin{tabular}{|c|c|c|c|c|c|c|c|c|}
\hline Item & \multicolumn{4}{|c|}{ IGBTs Applications } & \multicolumn{4}{|c|}{ MOSFETs Applications } \\
\hline Time & Mode $_{\mathrm{P} j \mathrm{I}}$ & H-bridge 1 & Mode $_{\mathrm{S} j \mathrm{I}}$ & H-bridge 2 & Mode $_{\mathrm{P} j \mathrm{M}}$ & H-bridge 1 & Mode $_{\mathrm{S} j \mathrm{M}}$ & H-bridge 2 \\
\hline \multirow{2}{*}{$\begin{array}{c}t_{0} \sim t_{1}^{\prime} \\
t_{1} \sim t_{2} / t_{2}^{\prime}\end{array}$} & \multirow{2}{*}{$\mathrm{M}_{\mathrm{P} 1 \mathrm{I}}$} & $\mathrm{D}_{1} / \mathrm{D}_{4}$ & \multirow{2}{*}{$\mathrm{M}_{\mathrm{S} 1 \mathrm{I}}$} & \multirow{2}{*}{$\begin{array}{l}\mathrm{D}_{6} / \mathrm{D}_{7} \\
\mathrm{D}_{6} / \mathrm{D}_{7}\end{array}$} & $\mathrm{M}_{\mathrm{P} 1 \mathrm{M}}$ & \multirow{5}{*}{$\begin{array}{l}\mathrm{D}_{1} / \mathrm{D}_{4} \\
\mathrm{Q}_{1} / \mathrm{Q}_{4} \\
\mathrm{Q}_{1} / \mathrm{Q}_{4} \\
\mathrm{Q}_{1} / \mathrm{Q}_{4} \\
\mathrm{Q}_{1} / \mathrm{Q}_{4}\end{array}$} & \multirow{3}{*}{$\mathrm{M}_{\mathrm{S} 1 \mathrm{M}}$} & \multirow{3}{*}{$\begin{array}{l}\mathrm{Q}_{6} / \mathrm{Q}_{7} \\
\mathrm{Q}_{6} / \mathrm{Q}_{7} \\
\mathrm{Q}_{6} / \mathrm{Q}_{7}\end{array}$} \\
\hline & & $\mathrm{D}_{1} / \mathrm{D}_{4}$ & & & \multirow{4}{*}{$\mathrm{M}_{\mathrm{P} 2 \mathrm{M}}$} & & & \\
\hline$t_{2} / t_{2}^{1} \sim t_{3}$ & \multirow{3}{*}{$\mathrm{M}_{\mathrm{P} 2 \mathrm{I}}$} & $\mathrm{Q}_{1} / \mathrm{Q}_{4}$ & Ms2I & $\mathrm{Q}_{6} / \mathrm{Q}_{7}$ & & & & \\
\hline$t_{3} \sim t_{4}$ & & $\mathrm{Q}_{1} / \mathrm{Q}_{4}$ & \multirow{4}{*}{$\mathrm{M}_{\mathrm{S} 3 \mathrm{I}}$} & $\mathrm{D}_{5} / \mathrm{D}_{8}$ & & & $\mathrm{M}_{\mathrm{S} 2 \mathrm{M}}$ & $\mathrm{D}_{5} / \mathrm{D}_{8}$ \\
\hline$t_{4} \sim t_{5}$ & & $\mathrm{Q}_{1} / \mathrm{Q}_{4}$ & & $\mathrm{D}_{5} / \mathrm{D}_{8}$ & & & \multirow{4}{*}{$\mathrm{M}_{\mathrm{S} 3 \mathrm{M}}$} & $\mathrm{Q}_{5} / \mathrm{Q}_{8}$ \\
\hline$t_{5} \sim t_{6}$ & $\mathrm{M}_{\mathrm{P} 3 \mathrm{I}}$ & $\mathrm{D}_{2} / \mathrm{D}_{3}$ & & $\mathrm{D}_{5} / \mathrm{D}_{8}$ & $\mathrm{M}_{\mathrm{P} 3 \mathrm{M}}$ & $\mathrm{D}_{2} / \mathrm{D}_{3}$ & & $\mathrm{Q}_{5} / \mathrm{Q}_{8}$ \\
\hline$t_{6} \sim t_{7} / t_{7}^{1}$ & \multirow{4}{*}{$\mathrm{M}_{\mathrm{P} 4 \mathrm{I}}$} & $\mathrm{D}_{2} / \mathrm{D}_{3}$ & & $\mathrm{D}_{5} / \mathrm{D}_{8}$ & \multirow{4}{*}{$\mathrm{M}_{\mathrm{P} 4 \mathrm{M}}$} & $\mathrm{Q}_{2} / \mathrm{Q}_{3}$ & & $\mathrm{Q}_{5} / \mathrm{Q}_{8}$ \\
\hline$t_{7} / t_{7}^{\prime} \sim t_{8}$ & & $\mathrm{Q}_{2} / \mathrm{Q}_{3}$ & $\mathrm{M}_{\mathrm{S} 4 \mathrm{I}}$ & $\mathrm{Q}_{5} / \mathrm{Q}_{8}$ & & $\mathrm{Q}_{2} / \mathrm{Q}_{3}$ & & $\mathrm{Q}_{5} / \mathrm{Q}_{8}$ \\
\hline$t_{8} \sim t_{9}$ & & $\mathrm{Q}_{2} / \mathrm{Q}_{3}$ & \multirow{2}{*}{$\mathrm{M}_{\mathrm{S} 1 \mathrm{I}}$} & $\mathrm{D}_{6} / \mathrm{D}_{7}$ & & $\mathrm{Q}_{2} / \mathrm{Q}_{3}$ & $\mathrm{M}_{\mathrm{S} 4 \mathrm{M}}$ & $\mathrm{D}_{6} / \mathrm{D}_{7}$ \\
\hline$t_{9} \sim t_{10}$ & & $\mathrm{Q}_{2} / \mathrm{Q}_{3}$ & & $\mathrm{D}_{6} / \mathrm{D}_{7}$ & & $\mathrm{Q}_{2} / \mathrm{Q}_{3}$ & $\mathrm{M}_{\mathrm{S} 1 \mathrm{M}}$ & $\mathrm{Q}_{6} / \mathrm{Q}_{7}$ \\
\hline
\end{tabular}

To calculate the dc part of the primary current, periodic time integrals are made for (1), and (2) is obtained. The periodic time integral of $v_{L_{\mathrm{m}}}$ keeps at zero when the converter reaches steady state with certain dc bias, otherwise the average value of magnetizing current will continue to change. Similarly, the third item of the right side of (2) is also zero when the converter reaches steady state.

$$
\begin{aligned}
\int_{0}^{T} v_{L_{\mathrm{m}}} \mathrm{d} t & =\int_{0}^{T} v_{\mathrm{AB}} \mathrm{d} t-\int_{0}^{T}\left(r_{\mathrm{p}} i_{\mathrm{p}}+v_{\mathrm{dpI}}\right) \mathrm{d} t-L_{r} \int_{0}^{T} \frac{\mathrm{d} i_{\mathrm{p}}}{\mathrm{d} t} \mathrm{~d} t \\
& =\Delta \lambda_{\mathrm{ABI}}-\int_{0}^{T}\left(r_{\mathrm{p}} i_{\mathrm{p}}+v_{\mathrm{dpI}}\right) \mathrm{d} t=0,
\end{aligned}
$$

where $T$ is the switching cycle. $\Delta \lambda_{\mathrm{ABI}}$ refers to the voltseconds across points $\mathrm{A}$ and $\mathrm{B}$ in one switching cycle. As aforementioned, for IGBTs applications, the unmatched turnon times has no influence on the volt-seconds $\Delta \lambda_{\mathrm{ABI}}$, while the unmatched turn-off times will affect $\Delta \lambda_{\mathrm{ABI}}$ directly. For example, when $\mathrm{Q}_{2} / \mathrm{Q}_{3}$ are early turned off, $\Delta \lambda_{\mathrm{ABI}}$ will increase over zero, on the contrary, when the turn-off times of $\mathrm{Q}_{2} / \mathrm{Q}_{3}$ are delayed, $\Delta \lambda_{\mathrm{ABI}}$ will fall below zero.

From Table II, one switching cycle contains four modes, so (3) can be obtained as

$$
\begin{aligned}
\Delta \lambda_{\mathrm{ABI}} & =\int_{0}^{T}\left(r_{\mathrm{p}} i_{\mathrm{p}}+v_{\mathrm{dpI}}\right) \mathrm{d} t \\
& =\int_{t_{0}}^{t_{2}} v_{\mathrm{dp} 1 \mathrm{I}} \mathrm{d} t+\int_{t_{2}}^{t_{5}} v_{\mathrm{dp} 2 \mathrm{I}} \mathrm{d} t+\int_{t_{5}}^{t_{7}} v_{\mathrm{dp} 3 \mathrm{I}} \mathrm{d} t+\int_{t_{7}}^{t_{10}} v_{\mathrm{dp} 4 \mathrm{I}} \mathrm{d} t+r_{\mathrm{p}} \int_{0}^{T} i_{\mathrm{p}} \mathrm{d} t, \\
& =v_{\mathrm{dp} 1 \mathrm{I}} \tau_{1 \mathrm{I}}+v_{\mathrm{dp} 2 \mathrm{I}} \tau_{2 \mathrm{I}}+v_{\mathrm{dp} 3 \mathrm{I}} \tau_{3 \mathrm{I}}+v_{\mathrm{dp} 4 \mathrm{I}} \tau_{4 \mathrm{I}}+r_{\mathrm{p}} \bar{I}_{\mathrm{dppI}} T,
\end{aligned}
$$

where $\bar{I}_{\text {depl }}$ is the average current of $i_{\mathrm{p}}$, namely, the dc part of $i_{\mathrm{p}} \cdot v_{\mathrm{dpji}}(j=1,2,3,4)$ are shown as (4), in which $v_{\mathrm{Q} j}$ and $v_{\mathrm{D} j}$ $(j=1,2,3,4)$ refer to the voltage drops across the switch $\mathrm{Q}_{j}$ and the anti-paralleled diode $\mathrm{D}_{j}$, respectively. $\tau_{j 1}(j=1,2,3,4)$ are the time intervals of the respective modes $\mathrm{M}_{\mathrm{pj} j}$, which are shown as (5). Some approximate treatments are made here to simplify the derivation procedure, including neglecting the effect of $r_{\mathrm{p}}$ on the duration $\tau_{j 1}$ of each mode and ignoring the extra short mode introduced by the unmatched turn-off times.

$$
\begin{gathered}
\left\{\begin{array}{l}
v_{\mathrm{dp} 1 \mathrm{I}}=-v_{\mathrm{D} 1}-v_{\mathrm{D} 4} \quad v_{\mathrm{dp} 2 \mathrm{I}}=v_{\mathrm{Q} 1}+v_{\mathrm{Q} 4} \\
v_{\mathrm{dp} 3 \mathrm{I}}=v_{\mathrm{D} 2}+v_{\mathrm{D} 3} \quad v_{\mathrm{dp} 4 \mathrm{I}}=-v_{\mathrm{Q} 2}-v_{\mathrm{Q} 3}
\end{array}\right. \\
\left\{\begin{array}{l}
\tau_{1 \mathrm{I}}=t_{\varphi} / 2-\bar{I}_{\mathrm{dcpl}} L_{r} /\left(V_{1}+N V_{2}\right) \\
\tau_{2 \mathrm{I}}=\left(T-t_{\varphi}\right) / 2+\bar{I}_{\mathrm{dcpl}} L_{r} /\left(V_{1}+N V_{2}\right) \\
\tau_{3 \mathrm{I}}=t_{\varphi} / 2+\bar{I}_{\mathrm{dcpl}} L_{r} /\left(V_{1}+N V_{2}\right) \\
\tau_{4 \mathrm{I}}=\left(T-t_{\varphi}\right) / 2-\bar{I}_{\mathrm{dcpI}} L_{r} /\left(V_{1}+N V_{2}\right)
\end{array}\right.
\end{gathered}
$$

Then, with (3), (4) and (5), one can be derived as (6).

$$
\bar{I}_{\mathrm{dcpI}}=\frac{\Delta \lambda_{\mathrm{ABI}}-\left(v_{\mathrm{dp} 1 \mathrm{II}}+v_{\mathrm{dp} 3 \mathrm{I}}\right) \frac{t_{\varphi}}{2}-\left(v_{\mathrm{dp} 2 \mathrm{I}}+v_{\mathrm{dp} 4 \mathrm{I}}\right)\left(\frac{T}{2}-\frac{t_{\varphi}}{2}\right)}{r_{\mathrm{p}} T-\left(v_{\mathrm{dp} 1 \mathrm{I}}-v_{\mathrm{dp} 2 \mathrm{I}}-v_{\mathrm{d} 3 \mathrm{I}}+v_{\mathrm{dp} 4 \mathrm{I}}\right) L_{r} /\left(V_{1}+N V_{2}\right)}
$$

It should be emphasized that the amplitude of $\bar{I}_{\mathrm{dcp}}$ cannot be too large, otherwise $i_{\mathrm{p}}$ will be larger or smaller than zero in the whole switching cycle, causing (4) and (5) to fail. Moreover, (3)-(6) work only when the current $i_{p}$ is continuous. Hence, it is required that the time intervals of $\mathrm{M}_{\mathrm{plI}} / \mathrm{M}_{\mathrm{p} 3 \mathrm{I}}$ and $\mathrm{M}_{\mathrm{s} 2 \mathrm{I}} / \mathrm{M}_{\mathrm{s} 4 \mathrm{I}}$ must be larger than the dead time. And the boundary condition of (6) should be checked up after calculation.

Similarly, the de part of $i_{\mathrm{s}}$ can be calculated with (7).

$$
\bar{I}_{\mathrm{dcpI}}=\frac{\Delta \lambda_{\mathrm{CDI}}-\left(v_{\mathrm{ds} 1 \mathrm{I}}+v_{\mathrm{ds} 3 \mathrm{I}}\right)\left(\frac{T}{2}-\frac{t_{\varphi}}{2}\right)-\left(v_{\mathrm{ds} 2 \mathrm{I}}+v_{\mathrm{ds} 41}\right) \frac{t_{\varphi}}{2}}{-r_{\mathrm{s}} T-\left(v_{\mathrm{d} 1 \mathrm{I}}-v_{\mathrm{ds} 2 \mathrm{I}}-v_{\mathrm{dd} 3 \mathrm{I}}+v_{\mathrm{ds} 4 \mathrm{I}}\right) L_{r} /\left(V_{1}+N V_{2}\right)},
$$

where $\Delta \lambda_{\mathrm{CDI}}$ refers to the volt-seconds across points $\mathrm{C}$ and $\mathrm{D}$ in one switching cycle. For instance, when $\mathrm{Q}_{5} / \mathrm{Q}_{8}$ are early turned off, $\Delta \lambda_{\mathrm{CDI}}$ will reduce below zero. On the contrary, when the turn-off times of $\mathrm{Q}_{5} / \mathrm{Q}_{8}$ are delayed, 
$\Delta \lambda_{\mathrm{ABI}}$ will increase over zero. $v_{\mathrm{dsi}}(i=1,2,3,4)$ are shown as $(8)$, in which $v_{\mathrm{Q} j}$ and $v_{\mathrm{D} j}(j=5,6,7,8)$ refer to the voltage drops across the switch $\mathrm{Q}_{j}$ and the anti-paralleled diode $\mathrm{D}_{j}$, respectively.

$$
\begin{cases}v_{\mathrm{ds} 1 \mathrm{I}}=v_{\mathrm{D} 6}+v_{\mathrm{D} 7} & v_{\mathrm{ds} 2 \mathrm{I}}=-v_{\mathrm{Q} 6}-v_{\mathrm{Q} 7} \\ v_{\mathrm{ds} 3 \mathrm{I}}=-v_{\mathrm{D} 5}-v_{\mathrm{D} 8} & v_{\mathrm{ds} 4 \mathrm{I}}=v_{\mathrm{Q} 5}+v_{\mathrm{Q} 8}\end{cases}
$$

With (6) and (7), the magnetic flux density dc component $B_{\mathrm{dc}}$ can be calculated with

$$
B_{\mathrm{dcI}}=\frac{N^{2} \mu_{0} \mu_{r} A_{e}}{l_{\mathrm{m}}}\left(\bar{I}_{\mathrm{dcpI}}-\bar{I}_{\mathrm{dcsI}} / N\right),
$$

where $\mu_{0}$ is the permeability of vacuum, and $\mu_{r}$ is the relative permeability, $A_{e}$ is the effective cross-sectional area, and $l_{\mathrm{m}}$ is the length of flux path.

With (6), (7) and(9), it is found that both $\bar{I}_{\mathrm{dcpI}}$ and $\bar{I}_{\text {dcs }}$ are only affected by the factors on their respective sides, including volt-seconds, winding resistance of the transformer and the voltage drops across devices. But they collaborate to result in the dc bias of the transformer. For the methods which detect the transformer directly and produce reverse excitation to counteract the dc bias, the magnetic flux density dc component $B_{\mathrm{dc}}$ can be eliminated. However, $\bar{I}_{\text {dcpI }}$ and $\bar{I}_{\text {dcsI }}$ still exist, which can cause uneven conduction and switching loss among switches and further result in inconsistent aging degree of the semiconductor devices. This may aggravate the inconsistency among devices and increase the dc bias of both sides in turn. With these methods [11], [14]-[18], the position (primary or secondary side or both sides) where the dc bias occurs cannot be ascertained, making it hard to eliminate the possible dc bias of $i_{\mathrm{p}}$ and $i_{\mathrm{s}}$. From this perspective, detecting the dc parts of $i_{\mathrm{p}}$ and $i_{\mathrm{s}}$ and regulating the duty cycles of switches at the side where dc bias occurs seems to be a better choice to avoid this potential ill effect.

\section{B. MOSFETS Applications}

For MOSFETs applications, (2) is still workable. Assuming that the on-state resistance of MOSFETs and voltage drops across body diodes are constant, (10) can be obtained according to Table II.

With (10), the reason why unmatched turn-on times only cause small dc bias in the MOSFETs applications (mentioned in Section III) can be easily obtained. When the turn-on time of switches are early or delayed, current $i_{p}$ can flow through the body diodes and the operating state keeps unchanged. For example, in Fig. 3, as long as the turn-on time of $\mathrm{Q}_{1}$ is later than $t_{0}$ and earlier than $t_{2}, \Delta \lambda_{\mathrm{ABM}}$ will keep unchanged, because it has been mentioned in Section II that $v_{\mathrm{AB}}$ is only affected by the voltages $V_{1}$ and $V_{2}$, the on/off states of $\mathrm{Q}_{1}-\mathrm{Q}_{8}$ and $\mathrm{D}_{1}-\mathrm{D}_{8}$. However, due to the difference between the voltage drops of body diodes and the voltages across MOSFETs channel, the first item on the left side varies, which results in the dc bias of $i_{\mathrm{p}}$ But this duration is too short, so the dc bias of $i_{\mathrm{p}}$ will be small.

$$
\begin{aligned}
\Delta \lambda_{\mathrm{ABM}}= & \int_{0}^{T}\left(R_{\mathrm{pM}} i_{\mathrm{p}}+v_{\mathrm{dpM}}\right) \mathrm{d} t \\
= & \int_{t_{0}}^{t_{1}} v_{\mathrm{dp} 1 \mathrm{M}} \mathrm{d} t+\int_{t_{1}}^{t_{5}} R_{\mathrm{p} 2 \mathrm{M}} i_{\mathrm{p}} \mathrm{d} t \\
& +\int_{t_{5}}^{t_{6}} v_{\mathrm{dp} 3 \mathrm{M}} \mathrm{d} t+\int_{t_{6}}^{t_{10}} R_{\mathrm{p} 4 \mathrm{M}} i_{\mathrm{p}} \mathrm{d} t+r_{\mathrm{p}} \int_{0}^{T} i_{\mathrm{p}} \mathrm{d} t \\
= & v_{\mathrm{dp} 1 \mathrm{M}} t_{\mathrm{d}}+R_{\mathrm{p} 2 \mathrm{M}} \int_{t_{1}}^{t_{5}} i_{\mathrm{p}} \mathrm{d} t+v_{\mathrm{dp} 3 \mathrm{M}} t_{\mathrm{d}} \\
& +R_{\mathrm{p} 4 \mathrm{M}} \int_{t_{6}}^{t_{10}} i_{\mathrm{p}} \mathrm{d} t+r_{\mathrm{p}} \bar{I}_{\mathrm{dcpM}} T
\end{aligned}
$$

One switching cycle contains four modes according to the on-state devices, and the expressions of $v_{\mathrm{dp} 1 \mathrm{M}}, R_{\mathrm{p} 2 \mathrm{M}}, v_{\mathrm{dp} 3 \mathrm{M}}$ and $R_{\mathrm{p} 4 \mathrm{M}}$ are shown as (11).

$$
\begin{cases}v_{\mathrm{dp} 1 \mathrm{M}}=-v_{\mathrm{D} 1}-v_{\mathrm{D} 4} & R_{\mathrm{p} 2 \mathrm{M}}=R_{\mathrm{Q} 1}+R_{\mathrm{Q} 4} \\ v_{\mathrm{d} 33 \mathrm{M}}=v_{\mathrm{D} 2}+v_{\mathrm{D} 3} & R_{\mathrm{p} 4 \mathrm{M}}=R_{\mathrm{Q} 2}+R_{\mathrm{Q} 3}\end{cases}
$$

By neglecting the variation of $i_{\mathrm{p}}$ during $\left[t_{3}, t_{5}\right]$ and $\left[t_{8}, t_{10}\right]$ and ignoring the extra short modes introduced by the unmatched turn-off times, the integrals of $i_{\mathrm{p}}$ during $\left[t_{1}, t_{5}\right]$ and $\left[t_{6}, t_{10}\right]$ can be calculated as (12).

$$
\begin{aligned}
& \int_{t_{1}}^{t_{5}} i_{\mathrm{p}} \mathrm{d} t=\bar{I}_{\mathrm{dcpM}}\left(\frac{T}{2}-t_{\mathrm{d}}\right)+\frac{k T t_{\varphi}}{4}+\frac{k t_{\varphi} t_{\mathrm{d}}}{2}-\frac{k}{2} t_{\varphi}^{2}-\frac{k}{2} t_{\mathrm{d}}^{2} \\
& \int_{t_{6}}^{t_{10}} i_{\mathrm{p}} \mathrm{d} t=\bar{I}_{\mathrm{dcpM}}\left(\frac{T}{2}-t_{\mathrm{d}}\right)-\frac{k T t_{\varphi}}{4}-\frac{k t_{\varphi} t_{\mathrm{d}}}{2}+\frac{k}{2} t_{\varphi}^{2}+\frac{k}{2} t_{\mathrm{d}}^{2}
\end{aligned}
$$

where $k$ is the rate of rise of $i_{\mathrm{p}}$ during $\left[t_{0}, t_{4}\right]$, namely, $\left(V_{1}+N V_{2}\right) / L_{r}$.

Therefore, $\bar{I}_{\mathrm{dcpM}}$ can be calculated as (13). Similarly, $\bar{I}_{\mathrm{dcs} M}$ can also be obtained as (14), with the expressions of $R_{s 1 \mathrm{M}}$, $v_{\mathrm{ds} 2 \mathrm{M}}, R_{\mathrm{s} 3 \mathrm{M}}$ and $v_{\mathrm{ds} 4 \mathrm{M}}$ shown as (15).

$$
\begin{gathered}
\bar{I}_{\mathrm{dcpM}}=\frac{\Delta \lambda_{\mathrm{ABM}}-\left(v_{\mathrm{dp} 1 \mathrm{M}}+v_{\mathrm{dp} 3 \mathrm{M}}\right) t_{\mathrm{d}}-\left(R_{\mathrm{p} 2 \mathrm{M}}-R_{\mathrm{p} 4 \mathrm{M}}\right)\left(T t_{\varphi}+2 t_{\varphi} t_{\mathrm{d}}-2 t_{\varphi}^{2}-2 t_{\mathrm{d}}^{2}\right)\left(V_{1}+N V_{2}\right) /\left(4 L_{r}\right)}{r_{\mathrm{p}} T+\left(R_{\mathrm{p} 2 \mathrm{M}}+R_{\mathrm{p} 4 \mathrm{M}}\right)\left(T / 2-t_{\mathrm{d}}\right)} \\
\bar{I}_{\mathrm{dcsM}}=\frac{\lambda_{\mathrm{CDM}}-\left(v_{\mathrm{ds} 2 \mathrm{M}}+v_{\mathrm{ds} 4 \mathrm{M}}\right) t_{\mathrm{d}}-\left(R_{\mathrm{s} \mathrm{M}}-R_{\mathrm{s} 3 \mathrm{M}}\right)\left(T t_{\varphi}+2 t_{\varphi} t_{\mathrm{d}}-2 t_{\varphi}^{2}-2 t_{\mathrm{d}}^{2}\right)\left(V_{1}+N V_{2}\right) /\left(4 L_{r}\right)}{-r_{\mathrm{s}} T-\left(R_{\mathrm{s} 1 \mathrm{M}}+R_{\mathrm{s} 3 \mathrm{M}}\right)\left(T / 2-t_{\mathrm{d}}\right)}
\end{gathered}
$$




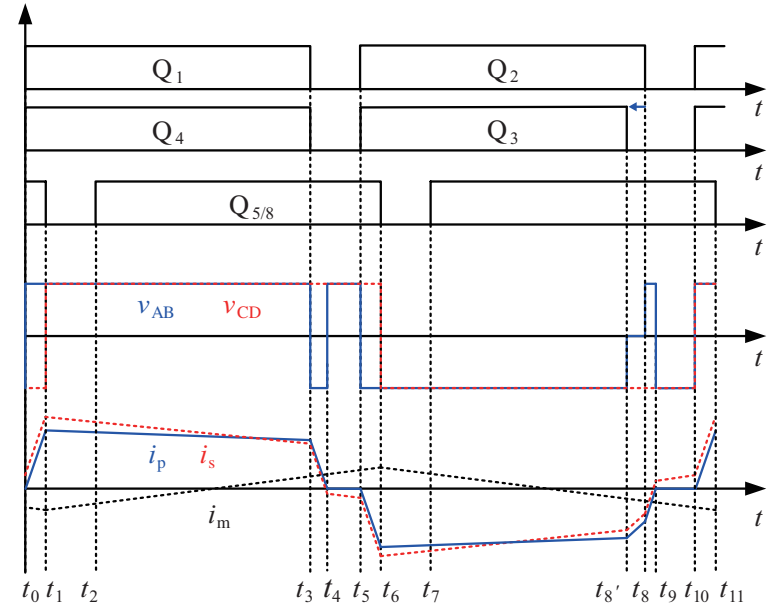

Fig. 5. The waveforms of the DAB converter when $\mathrm{Q}_{3}$ is early turned off and $i_{\mathrm{p}}$ is discontinuous.

$$
\begin{cases}R_{\mathrm{s} 1 \mathrm{M}}=R_{\mathrm{Q} 6}+R_{\mathrm{Q} 7} & v_{\mathrm{ds} 2 \mathrm{M}}=-v_{\mathrm{D} 5}-v_{\mathrm{D} 8} \\ R_{\mathrm{s} 3 \mathrm{M}}=R_{\mathrm{Q} 5}+R_{\mathrm{Q} 8} & v_{\mathrm{ds} 4 \mathrm{M}}=v_{\mathrm{D} 6}+v_{\mathrm{D} 7}\end{cases}
$$

Then, similar to (9), the dc magnetizing current can be calculated with (13) and (14). Similar to the IGBTs applications, the dc magnetizing current is caused by the dc bias on both primary and secondary sides, and the dc bias on primary and secondary sides has no effect on each other. Hence, it is also recommended that dc bias currents $\bar{I}_{\mathrm{dcpM}}$ and $\bar{I}_{\mathrm{dcsM}}$ should be treated separately.

\section{Analysis for Discontinuous Current Mode (DCM)}

The aforementioned analysis of dc bias magnetizing current is based on the condition that $i_{\mathrm{p}}$ and $i_{\mathrm{s}}$ are continuous, while for the discontinuous current mode (DCM) some conclusions changes. As shown in Fig. 5, when the power is transferred from $V_{1}$ to $V_{2}$, the phase-shift angle is too small to keep $i_{\mathrm{p}}$ continuous. But due to the magnetizing current $i_{\mathrm{m}}, i_{\mathrm{s}}$ can be kept continuous. When $\mathrm{Q}_{3}$ is early turned off, an extra operating mode will be introduced, and the volt-seconds $\Delta \lambda_{\mathrm{AB}}$ can be calculated as (16).

$$
\begin{aligned}
\lambda_{\mathrm{AB}}= & \int_{t_{0}}^{t_{5}} v_{\mathrm{AB}} \mathrm{d} t+\int_{t_{5}}^{t_{10}} v_{\mathrm{AB}} \mathrm{d} t \\
= & V_{1}\left(\frac{T}{2}-\frac{2 i_{\mathrm{p}}\left(t_{3}\right) L_{r}}{V_{1}+N V_{2}}\right) \\
& -V_{1}\left(\frac{T}{2}-t_{\mathrm{d}}-\frac{2 L_{r}}{-V_{1}-N V_{2}}\left(i_{\mathrm{p}}\left(t_{8}^{\prime}\right)-\frac{N V_{2}}{L_{r}} t_{\mathrm{d}}\right)\right) \\
= & V_{1} \frac{2\left(-i_{\mathrm{p}}\left(t_{8}^{\prime}\right)-i_{\mathrm{p}}\left(t_{3}\right)\right) L_{r}}{V_{1}+N V_{2}}
\end{aligned}
$$

For that the current $i_{\mathrm{p}}$ keeps almost unchanged during the durations $\left[t_{1}, t_{3}\right]$ and $\left[t_{6}, t_{8}\right], i_{\mathrm{p}}\left(t_{3}\right)$ is considered to be very close to $-i_{\mathrm{p}}\left(t_{8}^{\prime}\right)$ and $\Delta \lambda_{\mathrm{AB}}$ is very close to zero. Hence, the $\mathrm{dc}$ bias will be very tiny in this situation. However, since that $i_{\mathrm{s}}$ is still continuous, unmatched turn-off time of the switches still causes obvious dc bias. Although the shape of $i_{\mathrm{s}}$ varies, the dc bias current can still be predicted with (6), (7), (13) and (14) since that the time intervals of $\left[t_{4}, t_{5}\right]$ and $\left[t_{9}, t_{10}\right]$ are very short. Similarly, the inconsistency of devices at the primary side just results in very small dc bias, while the inconsistency of devices at the secondary side can cause large dc bias, which can be predicted with (6), (7), (13) and (14). Furthermore, when the phase-shift time is smaller than the dead zone, the transmission power will be zero if $V_{1}=N V_{2}$, and no dc bias will be generated.

The aforementioned analysis can be generalized as follow:

1) When the phase shift angle is small, the winding current of leading bridge will be discontinuous, while the winding current on lagging side keeps being continuous due to the magnetizing current;

2) Unmatched turn-on and turn-off time and inconsistency of devices in leading bridge only result in very tiny dc bias, which can hardly be measured;

3) Unmatched turn-on and turn-off time and inconsistency of devices in lagging bridge results in obvious dc bias, which can be calculated with (6), (7), (13) and (14);

4) When the phase-shift time reduces smaller than dead zone, no dc bias will be generated if $V_{1}=N V_{2}$.

\section{Analysis for $V_{1} \neq N V_{2}$}

Considering the situation $V_{1} \neq N V_{2}, i_{\mathrm{p}}$ and $i_{\mathrm{s}}$ will vary obviously during the time intervals $\left[t_{1}, t_{3}\right]$ and $\left[t_{6}, t_{8}\right]$. But as long as the difference between $V_{1}$ and $N V_{2}$ is not very large, (6), (7), (13) and (14) still work. But if $V_{1}$ and $N V_{2}$ mismatch seriously, $i_{\mathrm{p}}$ and $i_{\mathrm{s}}$ will cross zero during $\left[t_{1}, t_{3}\right]$ and $\left[t_{6}, t_{8}\right]$, and operating stage will change, so that the prediction accuracy of dc bias will decrease. Additionally, when $V_{1} \neq N V_{2}$, the transmission power is not zero even if the phase-shift time is smaller than the dead zone, so that the unmatched turnon/off times and inconsistency of devices will still result in dc bias. However, for the operating states in such situation and normal situation are totally different, the accuracy of the aforementioned expressions will decrease a lot.

\section{E. Generalization}

With the aforementioned analysis, for the DAB converters, the dc components of primary and secondary current are only affected by the factors on their respective sides, and they collaborate to cause the dc part of magnetizing current. Hence, the aforementioned calculation methods can be generalized to the multi-active-bridge converter, which is shown in Fig. 6. With (2), similar derivation procedure can be applied to calculate integrals and the dc part $\bar{I}_{\mathrm{dc} i}(i=1$, $2, \ldots, N)$ of current through each winding can be obtained. Hence, by reflecting $\bar{I}_{\mathrm{dc} i}$ to the $1 \#$ side uniformly, the dc magnetizing current can be expressed as the summation of the reflected dc current. 


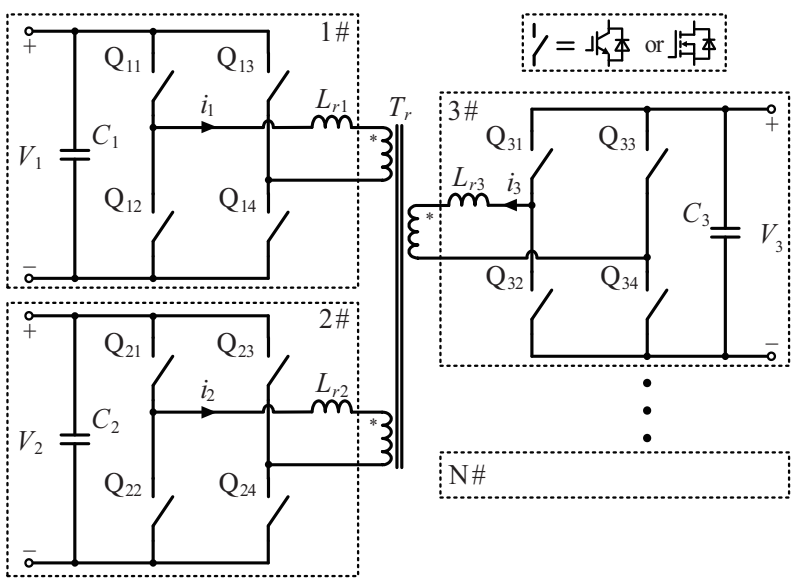

Fig. 6. The topology of multi-active-bridge converter.

\section{The Prediction Method of the DC Bias}

In order to obtain the maximum permitted inconsistency of devices and drivers, an example is taken here to introduce the detailed calculation procedure. The parameters are shown in Table III. Moreover, the maximum inconsistency of forward voltage or on-state resistance is set as $\pm 5 \%$.

The maximum unmatched turn-on/off time is set as 10 ns. Hence, considering that only one switch on primary side turns off $10 \mathrm{~ns}$ earlier or later than the expected time, $\Delta \lambda_{\mathrm{AB}}$ can reach the maximum value $\left(7.5 \times 10^{-6} \mathrm{Vs}\right)$ or the minimum value $\left(-7.5 \times 10^{-6} \mathrm{Vs}\right)$.

For IGBTs applications, if $\Delta \lambda_{\mathrm{ABI}}$ is fixed at $7.5 \times 10^{-6} \mathrm{Vs}$ and $\varphi$ is set as $50^{\circ}$, the curves of $\bar{I}_{\mathrm{dcpI}}$ versus $v_{\mathrm{dp} \mathrm{III}} \sim v_{\mathrm{dp} 4 \mathrm{I}}$ are shown in Fig. 7(a), in which each layer of curve represents a set of $v_{\mathrm{dp} 2 \mathrm{I}}$ and $v_{\mathrm{dp} 4 \mathrm{I}}$. The curves surrounded by dash dot lines and solid lines represent the data with $v_{\mathrm{dp} 2 \mathrm{I}}$ fixed at $3.23 \mathrm{~V}$ and $3.57 \mathrm{~V}$, respectively. It can be noted that $\bar{I}_{\text {dcpI }}$ increases with the decrease of $v_{\mathrm{dp} 1 \mathrm{I}} \sim v_{\mathrm{dp} 4 \mathrm{I}}$. The range of $\bar{I}_{\mathrm{dcpl}}$ versus the phaseshift angle $\varphi$ is shown in Fig. 7(b). As aforementioned, if $V_{1}=N V_{2}$, the dc bias will decrease to zero when the phaseshift time is shorter than the dead time. The dead time is set as $1 \mu \mathrm{s}$, so that when $\varphi$ is smaller than $3.6^{\circ}$, the dc bias will be zero. And noticeably, the situation that $V_{1}$ and $V_{2}$ mismatch is not considered here. The range of $\bar{I}_{\text {dcpI }}$ is given as the gray area, which is slightly broadened with the increase of $\varphi$. When $\varphi$ increases to $50^{\circ}$, the maximum and minimum values can reach $2.105 \mathrm{~A}$ and $-2.105 \mathrm{~A}$, with the maximum inconsistency limited within $\pm 5 \%$.

For MOSFETs applications, the curves of $\bar{I}_{\mathrm{dcpM}}$ versus $R_{\mathrm{p} 2 \mathrm{M}}$ and $R_{\mathrm{p} 4 \mathrm{M}}$ is shown in Fig. 8(a). Because the time intervals of modes $\mathrm{M}_{\mathrm{p} 1 \mathrm{M}}$ and $\mathrm{M}_{\mathrm{p} 3 \mathrm{M}}$ are very short, $v_{\mathrm{dp} 1 \mathrm{M}}$ and $v_{\mathrm{dp} 3 \mathrm{M}}$ have little effect on $\bar{I}_{\mathrm{dcpM}}$. Hence, they are fixed at $6.6 \mathrm{~V}$ here to simplify the analysis. In Fig. 8(a), $\bar{I}_{\mathrm{dcpM}}$ increases with the decrease of $R_{\mathrm{p} 2 \mathrm{M}}$ and increase of $R_{\mathrm{p} 4 \mathrm{M}}$. And $\bar{I}_{d c p \mathrm{M}}$ increases along with $\varphi$ according to Fig. 8(b). The maximum and minimum values can reach $1.269 \mathrm{~A}$ and $-1.269 \mathrm{~A}$ with $\varphi$ increasing to $50^{\circ}$.

It can be found that the rate of rise of the maximum value of $\bar{I}_{\mathrm{dcpI}}$ is smaller than $\bar{I}_{\mathrm{dcpM}}$. For the DAB converters employing MOSFETs, the differences between the on-
TABLE III

Main Parameters of DAB Converter

IGBTs Applications MOSFETs Applications

\begin{tabular}{|c|c|c|}
\hline Input voltage $V_{1}$ & \multicolumn{2}{|c|}{$750 \mathrm{~V}$} \\
\hline Output voltage $V_{2}$ & \multicolumn{2}{|c|}{$750 \mathrm{~V}$} \\
\hline Switching cycle $T$ & \multicolumn{2}{|c|}{$100 \mu \mathrm{s}$} \\
\hline Phase-shift angle $\varphi$ & \multicolumn{2}{|c|}{$50^{\circ}$} \\
\hline Dead time $t_{\mathrm{d}}$ & \multicolumn{2}{|c|}{$1 \mu \mathrm{s}$} \\
\hline Leakage inductor $L_{r}$ & \multicolumn{2}{|c|}{$200 \mu \mathrm{H}$} \\
\hline Magnetizing inductance $L_{\mathrm{m}}$ & \multicolumn{2}{|c|}{$20 \mathrm{mH}$} \\
\hline Turns ratio of $T_{r}$ & \multicolumn{2}{|c|}{$1: 1$} \\
\hline Winding resistance $r_{\mathrm{p}} / r_{\mathrm{s}}$ & \multicolumn{2}{|c|}{$100 \mathrm{~m} \Omega$} \\
\hline Device type & IHW25N120R2 & L227F18Y \\
\hline \multirow{2}{*}{ Device parameters } & $\begin{array}{c}\text { forward voltage } \\
\qquad(1.7 \mathrm{~V})\end{array}$ & $\begin{array}{l}\text { ON resistance } \\
\quad(33 \mathrm{~m} \Omega)\end{array}$ \\
\hline & $\begin{array}{c}\text { Diode forward } \\
\text { voltage drop }(3.1 \mathrm{~V})\end{array}$ & $\begin{array}{c}\text { Diode forward } \\
\text { voltage drop }(3.3 \mathrm{~V})\end{array}$ \\
\hline
\end{tabular}

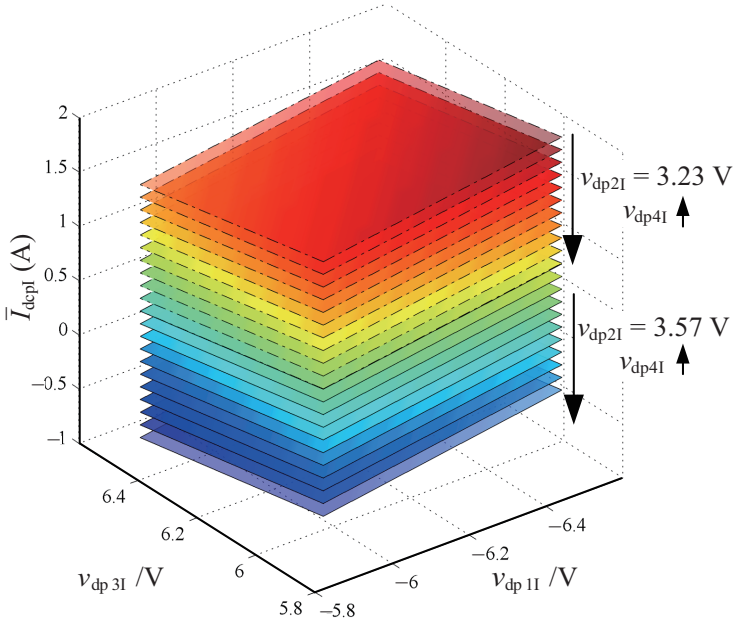

(a)

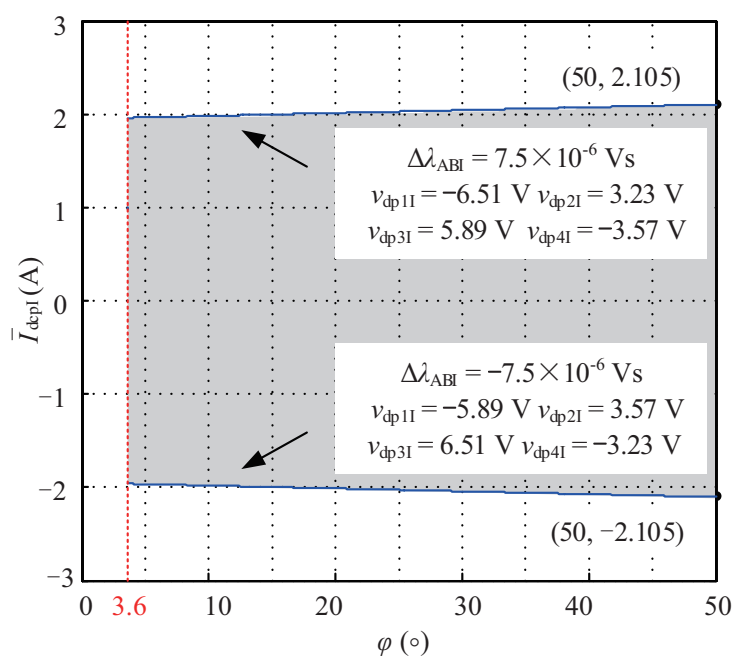

(b)

Fig. 7. The curves of $\bar{I}_{\text {dcpl. }}$ (a) Versus $v_{\text {dpII }} \sim v_{\text {dp41 }}$. (b) Versus phase-shift angle $\varphi$. 


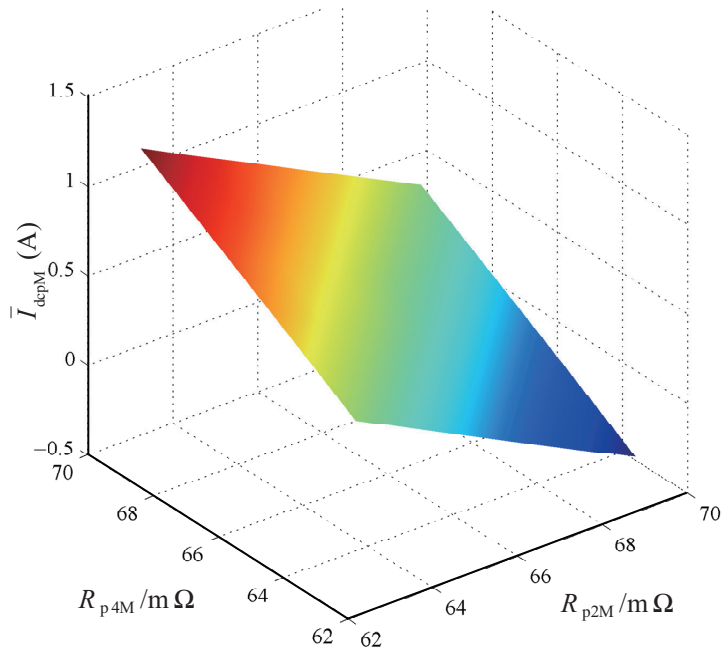

(a)

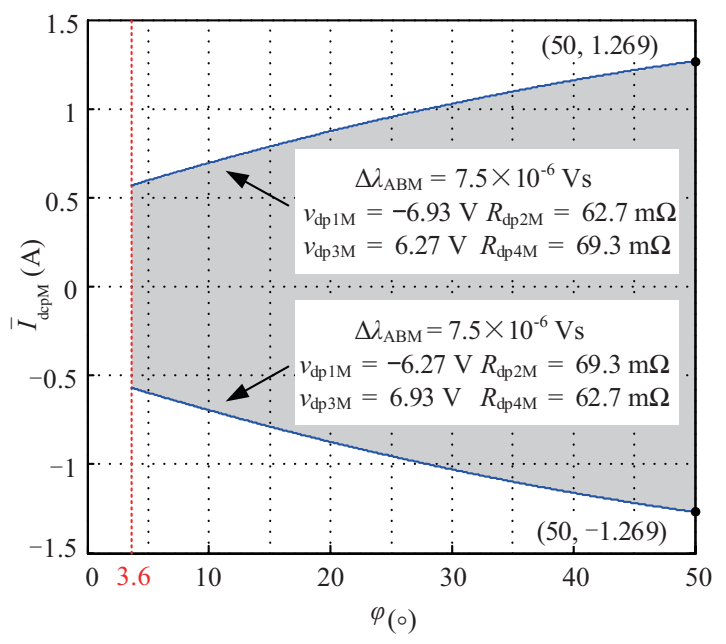

(b)

Fig. 8. The curves of $\bar{I}_{\mathrm{dcpM}}$. (a) Versus $R_{\mathrm{dp} 1 \mathrm{M}}$ and $R_{\mathrm{dp} 4 \mathrm{M}}$. (b) Versus phase-shift angle $\varphi$.

state resistance of MOSFETs are confirmed once the type and maximum inconsistency of MOSFETs are given. With the increase of phase shift-angle $\varphi$, the maximum value of $i_{\mathrm{p}}$ increases, which causes differences between the voltages across inconsistent MOSFETs to be magnified. Hence, the maximum of $\bar{I}_{\mathrm{dcpM}}$ increases rapidly. From another perspective, the item of numerator in (13), namely, $-2 t_{\varphi}{ }^{2}+t_{\varphi}\left(T+t_{\mathrm{d}}\right)-2 t_{\mathrm{d}}{ }^{2}$ is positive and is proportional to the square of $t_{\varphi}$. When $R_{\mathrm{p} 2 \mathrm{M}}$ is smaller than $R_{\mathrm{p} 4 \mathrm{M}}$, the third item of numerator in (13) is proportional to the square of $t_{\varphi}$, while the denominator keeps unchanged, resulting in the quadratic increase of the maximum of $\bar{I}_{\mathrm{dcp} M}$. However, for the DAB converters with IGBTs, the forward voltages of IGBTs and voltage drops of anti-paralleled diodes are assumed to be constant. Once the type of IGBTs is selected, the differences between the voltage across switches are determined, which do not vary with the increase of $\varphi$. Hence, according to (6), it can be found that the maximum of $\bar{I}_{\mathrm{dcpI}}$ increases linearly

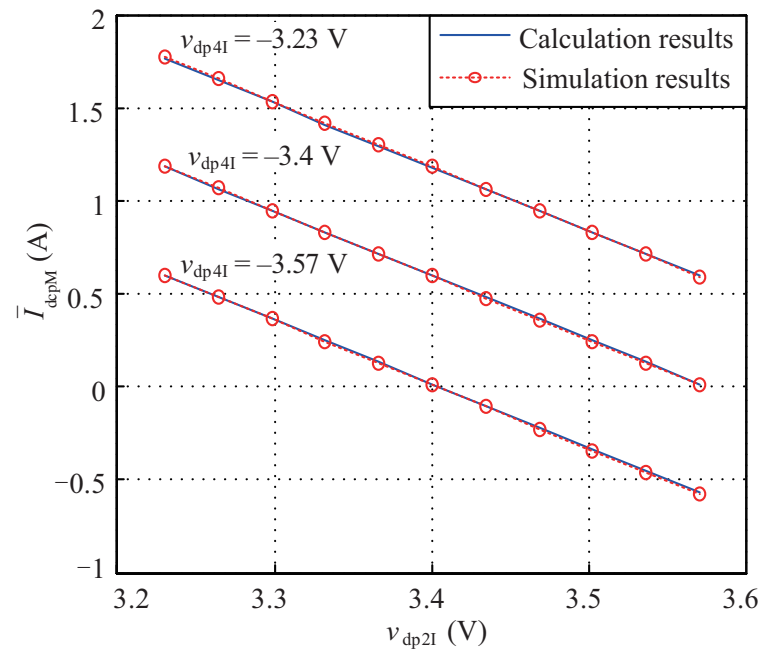

(a)

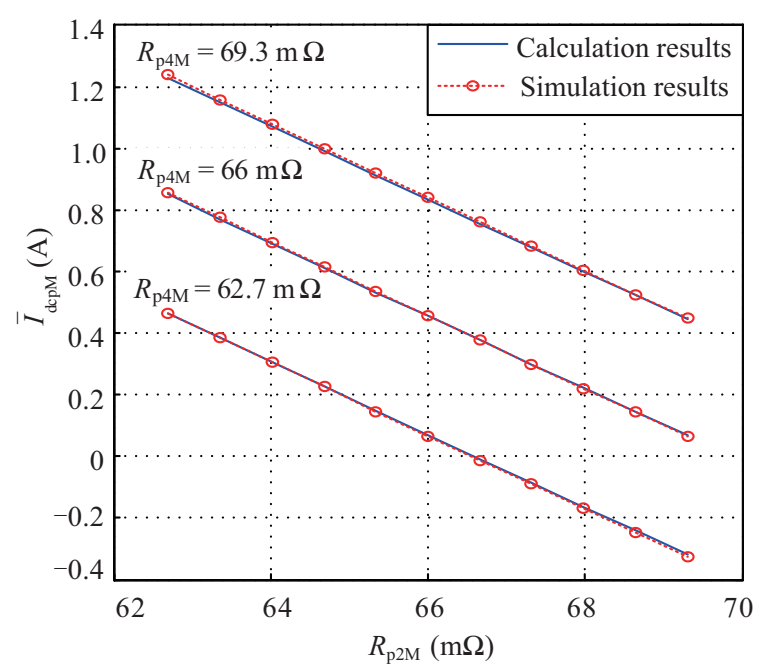

(b)

Fig. 9. The comparison between simulation and calculation results for (a) IGBTs applications. (b) MOSFETs applications.

along with $\varphi$. Actually, the rate of rise of the maximum value of $\bar{I}_{\mathrm{dcpI}}$ and $\bar{I}_{\mathrm{dcpM}}$ depends on the parameters of semiconductor switches and the given maximum inconsistency.

For some approximate treatments are made to simplify the derivation, the PLECS software is employed to verify the aforementioned results. For IGBTs applications, the error between simulation and calculation results is always smaller than 0.02 A with the given conditions, which is shown in Fig. 9(a). For MOSFETs applications, the comparison between simulation and calculation results is shown in Fig. 9(b), in which the error keeps being smaller than 0.02A. Hence, it can be concluded that the accuracy of aforementioned equations can be guaranteed.

\section{EXPERIMENTAL ANALYSIS}

In order to verify the aforementioned analysis, an experi mental prototype was built with the parameters given in Table IV. 
TABLE IV

EXPERIMENTAL PARAMETERS

\begin{tabular}{|c|c|c|}
\hline \multicolumn{2}{|c|}{ IGBTs Applications } & ETs Applications \\
\hline Input voltage $V_{1}$ & \multicolumn{2}{|c|}{$50 \mathrm{~V}$} \\
\hline Output voltage $V_{2}$ & \multicolumn{2}{|c|}{$50 \mathrm{~V}$} \\
\hline Switching cycle $T$ & \multicolumn{2}{|c|}{$100 \mu \mathrm{s}$} \\
\hline Phase-shift angle $\varphi$ & \multicolumn{2}{|l|}{$36^{\circ}$} \\
\hline Dead time $t_{\mathrm{d}}$ & \multicolumn{2}{|c|}{$1 \mu \mathrm{s}$} \\
\hline Leakage inductor $L_{r}$ & \multicolumn{2}{|c|}{$206.4 \mu \mathrm{H}$} \\
\hline $\begin{array}{l}\text { Magnetizing } \\
\text { inductance } L_{\mathrm{m}}\end{array}$ & \multicolumn{2}{|c|}{$19.64 \mathrm{mH}$} \\
\hline Turns ratio of $T_{r}$ & \multicolumn{2}{|l|}{$1: 1$} \\
\hline Winding resistance $r_{\mathrm{p}} / r_{\mathrm{s}}$ & \multicolumn{2}{|c|}{$60 \mathrm{~m} \Omega$} \\
\hline Device type & IKW30N60T & IXFX 55N50 \\
\hline \multirow[b]{2}{*}{$\begin{array}{l}\text { Device } \\
\text { parameters }\end{array}$} & $\begin{array}{c}\text { forward voltage } \\
(1.5 \mathrm{~V})\end{array}$ & $\begin{array}{l}\text { ON resistance } \\
(80 \mathrm{~m} \Omega)\end{array}$ \\
\hline & $\begin{array}{l}\text { diode forward } \\
\text { voltage drop } \\
(1.65 \mathrm{~V})\end{array}$ & $\begin{array}{l}\text { diode forward } \\
\text { voltage drop } \\
(1.5 \mathrm{~V})\end{array}$ \\
\hline
\end{tabular}

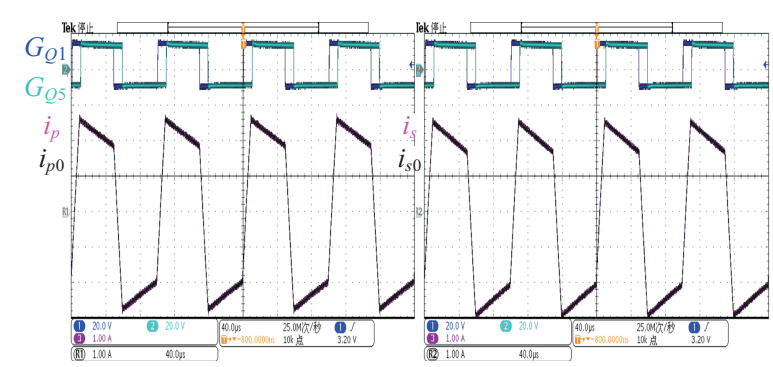

(a)

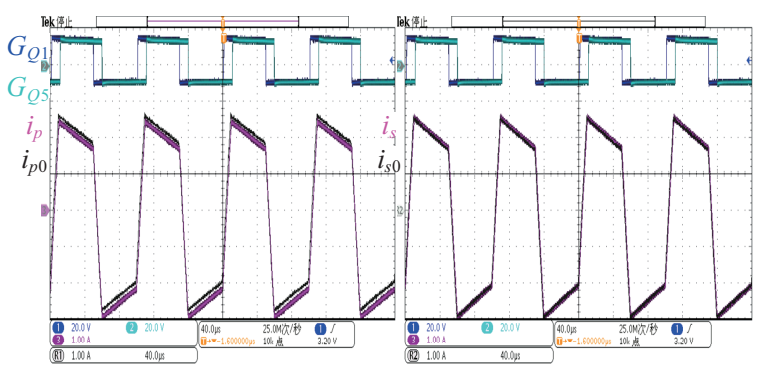

(b)

Fig. 10. The main waveforms of the DAB converters employing IGBTs. (a) Unmatched turn-on times. (b) Unmatched turn-off times.

The experimental results are shown in Figs. 10-12.

The waveforms of the DAB converter with IGBTs are given in Fig. 10. When the turn-on and turn-off times of $\mathrm{Q}_{1}$ are not early or delayed, the currents through the primary and secondary wingdings of the transformer are shown as $i_{\mathrm{p} 0}$ and $i_{\mathrm{s} 0}$, respectively. When $\mathrm{Q}_{1}$ is turned on 500 ns later than the expected time as shown in Fig. 10(a), the primary and secondary currents are shown as $i_{\mathrm{p}}$ and $i_{\mathrm{s}}$, which keep unchanged comparing to $i_{\mathrm{p} 0}$ and $i_{\mathrm{s} 0}$. However, when $\mathrm{Q}_{1}$ is set to be turned off $150 \mathrm{~ns}$ earlier than the expected time as shown in Fig. 10(b), the dc part of $i_{\mathrm{p}}$ decreases obviously while $i_{\mathrm{s}}$ keeps unchanged, which agrees with the aforementioned analysis.

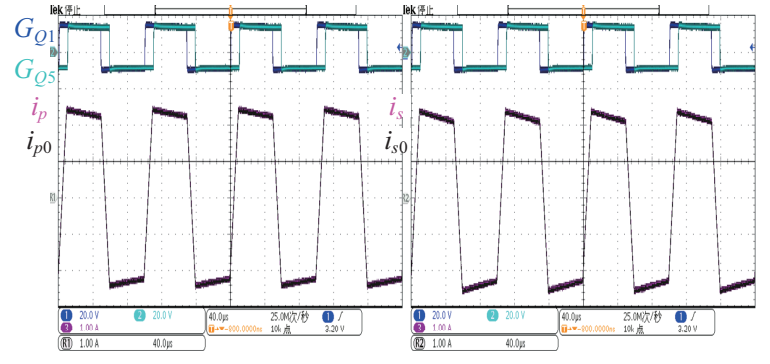

(a)

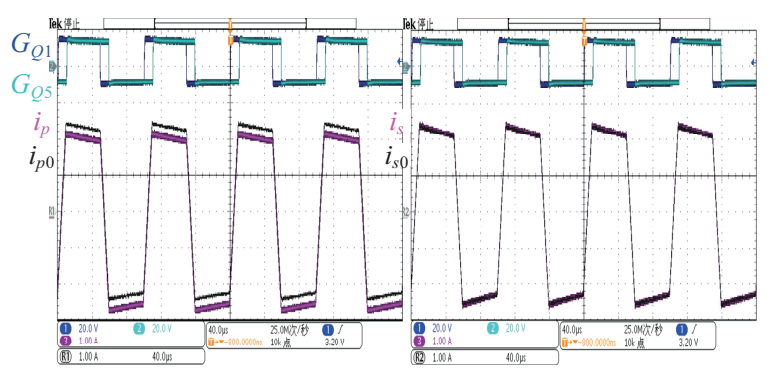

(b)

Fig. 11. The main waveforms of the DAB converters employing MOSFETs. (a) unmatched turn-on times. (b) unmatched turn-off times.

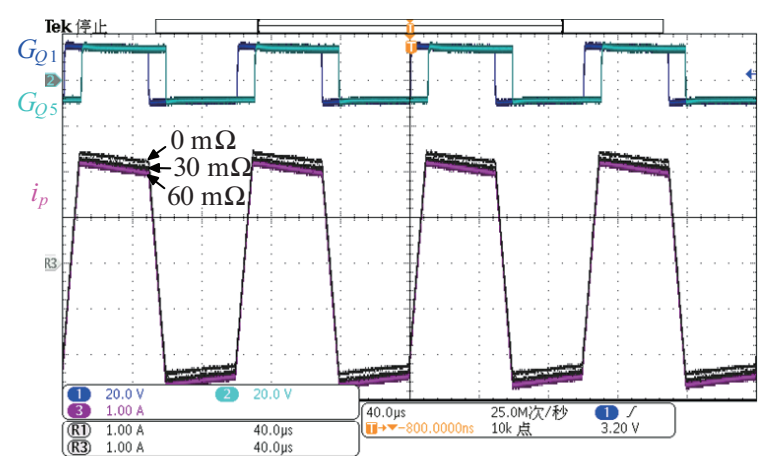

Fig. 12. The main waveforms of the DAB converters employing MOSFETs with different $R_{\mathrm{p} 2 \mathrm{M}}$.

The waveforms of the DAB converter with MOSFETs are shown in Fig. 11. Similarly, $i_{\mathrm{p} 0}$ and $i_{\mathrm{s} 0}$ refer to the original currents through the primary and secondary windings, respectively. When $\mathrm{Q}_{1}$ is turned on 500ns later than the expected time as shown in Fig. 11(a), the primary and secondary currents are shown as $i_{\mathrm{p}}$ and $i_{\mathrm{s}}$. The dc bias in $i_{\mathrm{p}}$ is affected slightly and the dc bias in $i_{\mathrm{s}}$ keeps unchanged. As mentioned in Section III, even though the turn-on time of $\mathrm{Q}_{1}$ is delayed, $i_{\mathrm{p}}$ can still flow through its body diode during this mode. Hence, the only difference introduced by the unmatched turn-on time of $\mathrm{Q}_{1}$ is the change of the voltage across $\mathrm{Q}_{1}$ in this duration. Also because this duration is too short, the effect on the dc part of $i_{\mathrm{p}}$ is hardly observed. When $\mathrm{Q}_{1}$ is turned off $150 \mathrm{~ns}$ earlier than the expected time, the dc part of $i_{\mathrm{p}}$ decreases obviously comparing to the initial situation, which is shown as Fig. 11(b). However, the dc part of $i_{\mathrm{s}}$ keeps unchanged for no change is put the secondary side. It can also be noted that there is an initial dc bias in the 
converte $r$ due to the inconsistency of devices.

In order to verify the relation between $\bar{I}_{\mathrm{dcpM}}$ and $R_{\mathrm{p} 2 \mathrm{M}}$, a small resistor is connected in series with $\mathrm{Q}_{1}$. By changing the resistance from 0 to $30 \mathrm{~m} \Omega$, and $60 \mathrm{~m} \Omega$, it can be noted that the dc part of $i_{\mathrm{p}}$ reduces gradually as in Fig. 12. As the duration of $M_{\mathrm{p} 1 \mathrm{M}}$ is so short that the effect of the extra resistor on $v_{\mathrm{dp} 1 \mathrm{M}}$ can be neglected, it can be concluded that $\bar{I}_{d c p \mathrm{M}}$ decreases with the increase of $R_{\mathrm{p} 2 \mathrm{M}}$, which agrees with Fig. 8(a).

\section{CONCLUSION}

In this paper, dc bias in the DAB converters with SPS control has been analyzed, and one prediction method of dc bias magnetizing current is proposed considering the inconsistency of switches and driving circuits, which can also be generalized to the multi-active-bridge converters. Some conclusions can be made here:

1) For IGBTs applications, unmatched turn-on times has no effect on the dc bias, while unmatched turn-off times will cause an obvious dc bias;

2) For MOSFETs applications, unmatched turn-on times has a very slight influence on the dc bias, while unmatched turn-off can introduce an obvious dc bias;

3) Unbalanced factors can only affect the dc bias current on the respective side, while they collaborate to create a dc flux density component in the transformer core.

With the prediction method, if the maximum permitted dc bias of the transformer is given, the range of the inconsistency of semiconductor switches and driver signals can be obtained, which is helpful for the selection of semiconductor devices and the design of the transformer. Hence, extra flux measurement and balancing methods can also be avoided.

\section{REFERENCES}

[1] L. Chang, W. Zhang, S. Xu, and K. Spence, "Review on distributed energy storage systems forutility applications," CPSS Transaction on Power Electronics and Applications, vol. 2, no. 4, pp. 267-276, Dec. 2017.

[2] B. Zhao, Q. Song, and W. Liu, "Efficiency characterization and optimization of isolated bidirectional DC-DC converter based on dual-phase-shift control for DC distribution application," IEEE Transactions on Power Electronics, vol. 28, no. 4, pp. 1711-1727, Apr. 2013.

[3] H. Bai and C. Mi, "Eliminate reactive power and increase system efficiency of isolated bidirectional dual-active-bridge DC-DC converters using novel dual-phase-shift control," IEEE Transactions on Power Electronics, vol. 23, no. 6, pp. 2905-2914, Nov. 2008.

[4] V. Karthikeyan and R. Gupta, "Closed-loop control of isolated dual active bridge converter using dual phase shift modulation," IECON 2015-41st Annual Conference of the IEEE Industrial Electronics Society, Yokohama, 2015, pp. 2800-2805.

[5] F. Krismer and J. W. Kolar, "Closed form solution for minimum conduction loss modulation of DAB converters," IEEE Transactions on Power Electronics, vol. 27, no. 1, pp. 174-188, Jan. 2012.

[6] F. Krismer and J. W. Kolar, "Efficiency-optimized high-current dual active bridge converter for automotive applications," IEEE Transactions on Industrial Electronics, vol. 59, no. 7, pp. 2745-2760, Jul. 2012.
[7] N. Hou, W. Song and M. Wu, "Minimum-current-stress scheme of dual active bridge DC-DC converter with unified phase-Shift control," IEEE Transactions on Power Electronics, vol. 31, no. 12, pp. 8552-8561, Dec. 2016.

[8] H. Akagi, S. Kinouchi, and Y. Miyazaki, "Bidirectional isolated dualactive-bridge (DAB)DC-DC converters using 1.2-kV 400-A SiCMOSFET dual modules," CPSS Transaction on Power Electronics and Applications,vol.1, no.1,pp. 33-40, Dec. 2016.

[9] B. Zhao, Q. Song, W. Liu and Y. Zhao, "Transient DC bias and current impact effects of high-frequency-isolated bidirectional DCDC converter in practice," CPSS Transaction on Power Electronics and Applications, vol. 31, no. 4, pp. 3203-3216, Apr. 2016.

[10] S. T. Lin, X. Li, C. Sun and Y. Tang, "Fast transient control for power adjustment in a dual-active-bridge converter," Electronics Letters, vol. 53, no. 16, pp. 1130-1132, Aug. 2017.

[11] G. Ortiz, L. Fässler, J. W. Kolar and O. Apeldoorn, "Flux balancing of isolation transformers and application of "the magnetic ear" for closed-loop volt-second compensation," IEEE Transactions on Power Electronics, vol. 29, no. 8, pp. 4078-4090, Aug. 2014.

[12] R. Redl, N. O. Sokal and C. W. Schaefer, "Transformer saturation and unusual system oscillation in capacitively coupled half-bridge or fullbridge forward converters: causes, analyses, and cures," PESC ' 88 Record., 19th Annual IEEE Power Electronics Specialists Conference, Kyoto, Japan, 1988, pp. 820-829, vol. 2.

[13] K. O'Meara, "Passive balancing of transformer flux in power converters," in Proc. 10th Nat. Solid-State Power Convers. Conf., Mar. 1983, vol. A1, pp. 1-11.

[14] S. Klopper and J. A. Ferreira, "A sensor for balancing flux in converters with a high-frequency transformer link," IEEE Transactions on Industry Applications, vol. 33, no. 3, pp. 774-779, May/Jun. 1997.

[15] R. Patel, "Detecting impending core saturation in switched-mode power converters," in Proc. 7th Nat. Solid-State Power Convers. Conf., Mar. 1980, vol. B3, pp. 1-11.

[16] W. M. Polivka, A. Cocconi, and S. Cuk, "Detection ofmagnetic saturation in switching converters," in Proc. Power Convers. Int. Conf., Mar. 1982, pp. 584-597.

[17] S. Dutta and S. Bhattacharya, "A method to measure the DC bias in high frequency isolation transformer of the dual active bridge DC to DC converter and its removal using current injection and PWM switching," in 2014 IEEE Energy Conversion Congress and Exposition (ECCE), Pittsburgh, PA, 2014, pp. 1134-1139.

[18] B. P. Baddipadiga and M. Ferdowsi, "Dual loop control for eliminating DC-bias in a DC-DC dual active bridge converter," in 2014 International Conference on Renewable Energy Research and Application (ICRERA), Milwaukee, WI, 2014, pp. 490-495.

[19] D. Costinett, D. Seltzer, D. Maksimovic and R. Zane, "Inherent voltsecond balancing of magnetic devices in zero-voltage switched power converters," in 2013 Twenty-Eighth Annual IEEE Applied Power Electronics Conference and Exposition (APEC), Long Beach, CA, 2013, pp. 9-15.

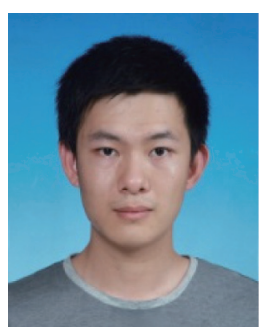

Liangcai Shu was born in Jiangsu, China, in 1994. He received the B.S. degree in electrical engineering from Nanjing University of Science and Technology (NJUST), Jiangsu, China in 2016 and is currently pursuing the M.S. degree in electrical engineering from Southeast University (SEU), Nanjing, China. His research interests include high-voltage highpower converters and soft-switching technique. 


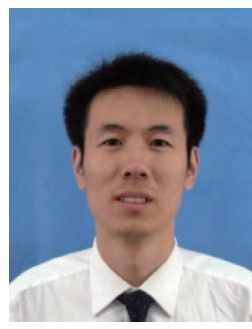

Wu Chen received the B.S., M.S., and Ph.D. degrees in electrical engineering from Nanjing University of Aeronautics and Astronautics (NUAA), Nanjing, China, in 2003, 2006, and 2009, respectively. From 2009 to 2010, he was a Senior Research Assistant at the Department of Electronic Engineering, City University of Hong Kong, Kowloon, Hong Kong. In 2010 and 2011, he was a Postdoctoral Researcher in Future Electric Energy Delivery and Management Systems Center, North Carolina State University, Raleigh. Since September 2011, he has been an Associate Research Fellow with the School of Electrical Engineering, Southeast University, Nanjing, China, and since May 2016, he has been a Professor. His main research interests include soft-switching converters, microgrid, and power electronic application. Dr. Chen is an Associate Editor for the IEEE TransactionsonIndustrial Electronics, the Journal of Power Electronics and the CPSS Transactions on Power Electronics and Applications.

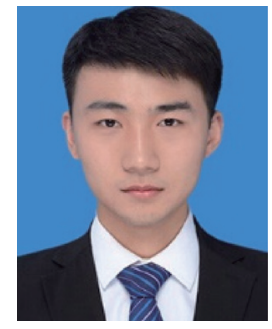

Zhanfei Song was born in Shandong, China, in 1995. He received the B.S. degree in electrical engineering from Shandong University, Jinan, China, in 2017. He is currently working toward the M.Sc. degree at Southeast University, Nanjing, China. His current research interests include topology and design of power electronic transformer, control method of grid-connected inverter, and the technology of bidirectional dc-dc converter. 